\title{
A imagem da criatividade para os internautas do Google Brasil
}

THE SIGNIFICANCE OF CREATIVITY FOR THE BRAZILIAN GOOGLE USERS

\section{Asdrúbal Borges Formiga Sobrinho}

Doutor em Psicologia, mestre em Comunicação Social e bacharel em Publicidade e Propaganda pela Universidade de Brasília (UnB). Professor adjunto da Faculdade de Comunicação e do Programa de Pós-graduação em Comunicação da UnB. Pesquisa sobre criatividade na comunicação.

E-mail: asdru_bal@uol.com.br

\section{Érica Abe}

Mestranda no Programa de Pós-Graduação em Comunicação da UnB.

E-mail: erica.abe@gmail.com

Recebido em 3 de maio de 2017. Aprovado em 4 de setembro de 2017.

\section{Resumo}

Este artigo utiliza o conceito de big data para investigar o que os termos de busca digitados no Google podem indicar sobre como os internautas significam a criatividade. Para isso, realizou-se levantamento bibliográfico dos trabalhos de comunicação que utilizam o Google Trends e, em seguida, análise de conteúdo dos 50 termos de busca que incluíam o termo "criatividade" em pesquisas no Brasil, pela página principal do Google, entre 2004 e 2014. Os resultados apontam possíveis correspondências entre a imagem da criatividade e as definições acadêmicas.

Palavras-chave: Criatividade. Comunicação. Google Trends.

\section{Abstract}

This article uses the big data concept to investigate which search terms typed on Google can indicate how internet users signify creativity. For this, a bibliographical survey of the communication works that use Google Trends was carried out, along with a content analysis of 50 search terms that included the term "creativity" in searches conducted in Brazil, by the main page of Google, between 2004 and 2014. The results show possible correspondences between the image of creativity and academic definitions.

Keywords: Creativity. Communication. Google Trends. 


\section{Introdução}

A popularização do acesso à informação deu origem a um novo comportamento no Brasil: fazer buscas pela internet. De acordo com a Pesquisa Brasileira de Mídia 2015 (BRASIL, 2014), o percentual diário de usuários passou de 26\% para 37\% entre 2013 e 2014, e o Google se tornou referência no assunto. Em dezembro de 2014, uma pesquisa da Serasa Experian mostrou que a ferramenta foi responsável por 94,3\% das buscas (OLHAR DIGITAL, 2015). Foi inclusive criado o verbo: "googlar" (GOOGLAR, 2017).

Paralelamente, há um crescente interesse da sociedade pelo tema "criatividade", já identificado em períodos históricos bem anteriores ao nosso, pois:

A visão da criatividade como um elemento crucial para o bem-estar econômico e social data, pelo menos, do império chinês de Han Wu-Di, que reinou até o ano 87 da Era Comum. [...] Francis Bacon e René Descartes, dois dos fundadores da ciência moderna, viram a criatividade científica como aproveitamento essencial das forças da natureza para melhoria das condições humanas. (CROPLEY, 2010, p. 3)

Um exemplo recente é o discurso do presidente da Comissão Europeia, José Manuel Barroso, que ressaltou o quão essencial é a criatividade para o bem-estar coletivo e individual, e também em respostas para a recente crise financeira, econômica e social (BARROSO, 2009).

Esse cenário despertou curiosidade sobre a correspondência entre as buscas via Google e as pesquisas acadêmicas sobre criatividade. Para isso, optamos por analisar o big data referente ao tema. Esse termo foi cunhado na Ciência da Computação e é utilizado para descrever dados variados, verossímeis, em grande volume e obtidos velozmente (VARSHNEY et al., 2013, p. 14). Na pesquisa, utilizamos o Google Trends (GOOGLE TRENDS, 2015a), que possibilita a análise dos dados referentes aos termos de busca utilizados pelos internautas no Google (GOOGLE TRENDS, 2015b), indicando quais contêm a palavra "criatividade". Não tratamos dos sites elencados como resultados nas pesquisas do Google, e sim da etapa anterior, ou seja, das frases e expressões digitadas pelos internautas.

O Google Trends não fornece o número absoluto de dados das pesquisas. Os resultados representam o volume relativizado de consultas conforme o ponto mais frequente, que recebe o valor de 100. Assim, cada resposta encontrada é dividida pelo maior número e multiplicada por 100. O valor 0 é mostrado quando não há dados suficientes (GOOGLE TRENDS, 2015c)ํ․

1 O Google adota a política de considerar apenas as buscas mais relevantes. Assim, a ferramenta elimina buscas repetidas pela mesma pessoa em um curto período de tempo. Apóstrofos e outros caracteres especiais também não são considerados (GOOGLE TRENDS, 2015c). 
Paralelamente ao interesse por estudos sobre criatividade, o acesso a este big data ampliou a motivação para descobrir e entender o que as pessoas querem saber quando usam a internet como meio de comunicação para procurar por criatividade. Entendendo a comunicação como forma de transformar informação em significado (MARCONDES FILHO, 2016), nosso interesse está num nível elementar relacionado com a compreensão, com a imagem de um conceito ou de uma prática. Este contexto nos levou à formulação do problema de pesquisa: o que os termos de busca digitados no Google podem indicar sobre a forma como os internautas significam a criatividade?

O objetivo principal é identificar a imagem que os internautas possuem da criatividade, a partir das buscas realizadas pelo Google; e o secundário é conhecer as possíveis correspondências entre essa significação e as definições acadêmicas bem como compreender por que os termos são empregados nas buscas. Para demonstrar como os objetivos foram atingidos, a próxima seção mostra um levantamento dos trabalhos de comunicação que utilizam o Google Trends para analisar a recorrência ou pertinência de determinados conceitos a partir dos termos de busca digitados no Google. Em seguida, analisamos os principais termos de busca e sua relação com os conceitos acadêmicos de "criatividade". Posteriormente, observamos os resultados da aplicação do método e, por fim, discutimos os resultados.

\section{Revisão de literatura}

Esta etapa seguiu as orientações de $\operatorname{Stumpf}$ (2012, p. 52): "para estabelecer as bases em que vão avançar, alunos precisam conhecer o que já existe, revisando a literatura existente sobre o assunto". Assim, nossa pesquisa começa pela definição precisa do tema do estudo, passa pela elaboração de um rol de palavras-chave, incluindo sua tradução para outros idiomas, e segue pela delimitação do período e da área geográfica das buscas. Lopes (2014, p. 139) aponta que esse momento deve contemplar textos que tratem dos modelos teóricos, problemas metodológicos e conteúdos temáticos relativos ao objeto da investigação. Por isso, pesquisamos trabalhos que também utilizam o Google Trends para pesquisas de comunicação, especialmente para identificar a imagem que os internautas têm sobre um conceito.

O levantamento considerou os artigos revisados por pares nas bases de dados do Portal de Livre Acesso à Produção em Ciências da Comunicação (Portcom), um repositório institucional da Sociedade Brasileira de Estudos Interdisciplinares da Comunicação (Intercom); do Portal de Periódicos da Universidade de Brasília (UnB) e do Portal de Periódicos da Coordenação de Aperfeiçoamento de Pessoal de Nível Superior (Capes) a 
partir de palavras-chave relacionadas a essa temática entre os anos de 2006 e 2016. Foram cruzados os detratores Google, Trends e Communication/Comunicação conforme as especificações: no Portcom, as buscas foram feitas no resumo das publicações; no banco da UnB, na opção "em todas as revistas"; e na base de dados da Capes, utilizamos a seleção "qualquer", que verifica a presença dos termos buscados nos campos título, autor ou resumo. Os resultados foram: nenhuma publicação na base Portcom, nenhuma obra na base da UnB e 23 itens na base de periódicos da Capes, todas a partir do cruzamento Google, Trends e Communication.

Conforme a análise de conteúdo proposta por Bardin (2012, p. 132), a pré-análise cumpriu as seguintes etapas: leitura flutuante, formulação de hipóteses e objetivos, e escolha dos documentos. Em seguida, referenciamos os índices, com elaboração dos indicadores, e criamos regras de recorte e categorização. A constituição do corpus e a administração da técnica nele foram as etapas seguintes, que levaram à síntese e seleção dos resultados. Assim, os 23 itens foram organizados em uma tabela com os seguintes critérios: detrator, título, link, base de dados, modalidade do trabalho, ano de publicação, área da pesquisa, fonte e tema. Além de todos os itens terem sido encontrados a partir dos detratores Google, Trends e Communication, eles foram escritos no formato de artigos e publicados entre 2007 e 2016 em 20 revistas diferentes. A análise do título e da descrição desses periódicos, em seus sites oficiais, mostra que apenas três tratam de comunicação social, mas nenhum deles escrito em língua portuguesa: First Monday; Journal of Communication Inquiry e Revista Latina de Comunicación Social. As demais versam sobre outras áreas, sendo mais frequentes as ligadas à saúde e à computação, apesar de administração, biologia, economia e meteorologia também aparecerem.

Já os três artigos publicados nas revistas de comunicação mostraram que o Google Trends foi utilizado para quantificar a ineficácia da censura governamental no Paquistão e na Turquia (NABI, 2014); analisar comparativamente as agendas midiáticas e de cidadania sobre o aquecimento global, em jornais espanhóis (FERNÁNDEZ-REYES; PIÑUEL-RAIGADA; VICENTE-MARIÑO, 2015); e examinar a duração da polêmica sobre o Ground Zero Mosque ${ }^{2}$, em cobertura da mídia e volume de buscas na internet (DEFOSTER, 2014).

Diante da inexistência de resultados que utilizam a ferramenta para investigar a imagem de um assunto na internet, ampliamos a busca e incluímos detratores utilizados em artigos sobre o tema: web data; digital methods; métodos digitais; virtual methods; métodos virtuais; internet archive; e arquivos internet. Todos foram combinados com

2 Trata-se de uma controvérsia envolvendo a construção e a demolição de um centro cultural islâmico a dois blocos de distância das ruínas do World Trade Center, em Nova York (OCONNOR, 2015). 
comunicação e communication $^{3}$, e foram encontrados mais 199 resultados, divididos da seguinte forma (Tabela 1):

\begin{tabular}{c|c} 
Palavra-chave & Quantidade de resultados \\
Arquivos internet & 18 \\
\hline Digital methods & 39 \\
\hline Digital methods communication & 4 \\
\hline Digital methods comunicação & 7 \\
\hline Métodos digitais & 5 \\
\hline Métodos digitais comunicação & 4 \\
\hline Métodos virtuais & 12 \\
\hline Virtual methods communication & 4 \\
\hline Web data & 100 \\
\hline Web data communication & 5 \\
\hline
\end{tabular}

Tabela 1. Resultados da pesquisa bibliográfica por palavra-chave

Fonte: Elaborada pelos autores (2016).

A análise dos bancos de dados mostra, mais uma vez, que o maior número de documentos está na base da Capes, com 143 itens. Nas bases UnB e Portcom foram encontrados 24 e 32 resultados, respectivamente. Para manter o padrão metodológico, os elementos foram organizados na mesma tabela, sob os mesmos critérios: detrator, título, link, base de dados, modalidade do trabalho, ano de publicação, área da pesquisa, fonte e tema. Na catalogação, consideramos apenas os artigos publicados entre 2006 e 2016 em periódicos. Após a exclusão de 25 registros duplicados, chegamos a 174 textos.

A análise dos títulos e da descrição dos periódicos nos sites oficiais mostra que, dos 174 resultados, 41 foram publicados em revistas de comunicação e outros 7 em revistas multidisciplinares. Outros resultados incluem computação, medicina, linguística, meio ambiente, antropologia, psicologia e sociologia. Dos 41 textos publicados em revistas de comunicação, apenas um trata da relação entre imagem e dados obtidos via internet: Fotografia e big data: implicações metodológicas (GOVEIA; CARREIRA, 2013). O artigo, porém, não trabalha com dados do Google Trends, assim como os demais.

Já a análise dos títulos, resumos e textos completos dos sete artigos publicados nas revistas multidisciplinares indicou uma diversidade maior em relação à área de conhecimento, mas também não foi encontrado um que utilizasse o Google Trends para analisar a imagem de um conceito a partir dos termos de busca, considerando ou

3 As buscas na base de dados Portcom não incluíram estes termos por ser um repositório exclusivo de comunicação. 
não os estados e as cidades onde as buscas foram realizadas ou, ainda, as semanas de maior incidência.

Diante do resultado, a pesquisa é uma oportunidade de introduzir na comunicação social uma técnica já amplamente trabalhada em outras áreas: a utilização do Google Trends para identificar comportamentos. Segundo Lopes (2014, p. 105): “o amadurecimento metodológico no campo da comunicação depende do desenvolvimento das análises de seus múltiplos níveis e dimensões, o que exige necessariamente uma variedade de metodologias". Isso nos permite partir para a explicitação do método e a análise das expressões utilizadas pelos internautas para procurar por criatividade na internet.

\section{Análise de conteúdo}

Para investigar a imagem dos internautas sobre criatividade, a partir dos termos de busca utilizados no Google, adotamos técnicas de análise de conteúdo que pressupõem organização e classificação das informações para entendermos seus significados. Os procedimentos fundamentam-se nas seguintes proposições de Bardin (2012, p. 44): "a intenção da análise de conteúdo é a inferência de conhecimentos relativos às condições de produção (ou, eventualmente, de recepção), inferência esta que recorre a indicadores (quantitativos ou não)". Além disso, o ato de inferir localiza-se entre o momento descritivo e o interpretativo, e permite, assim, responder perguntas sobre as causas e também sobre as consequências de um enunciado.

Somente foi possível recolher os dados devido à vigilância distribuída, que é o "modo de funcionamento das redes que constituem a vigilância como dispositivo nas sociedades contemporâneas" (Bruno, 2013, p. 28), sendo que "a facilidade em estocar e recuperar informações a partir do monitoramento cotidiano das ações dos indivíduos é uma característica mais ampla das sociedades informacionais e vem se intensificando velozmente nas últimas décadas" (Ibid., p. 145). Esse modelo não trata dos dispositivos que fazem da coleta de dados seu objetivo primeiro, mas de uma consequência de suas funcionalidades que possuem objetivos diversos.

Assim, a primeira etapa foi a apuração de dados fornecidos pelo Google Trends, ferramenta criada pelo próprio Google que "analisa um percentual de buscas realizadas pelos motores de busca do Google para entender quantas buscas foram realizadas em um determinado período de tempo" (GOOGLE TRENDS, 2015d). Nesse estudo, tivemos acesso aos termos digitados na caixa de busca, e foi necessário fazer delimitações. A primeira foi restringir a pesquisas que incluíam o termo "criatividade". A segunda, utilizar apenas pesquisas feitas no Brasil pela página principal do Google, que leva aos resultados 
gerais, sem filtro de categorias, pois a ferramenta oferece a opção de resultados filtrados em diferentes categorias, tais como imagens, notícias, vídeos etc. No entanto, restringimos o estudo às buscas que procuravam os resultados exibidos na página principal, ou seja, as páginas indexadas com o termo "criatividade". A terceira, utilizar apenas buscas entre 2004 e 2014. A data inicial, 4/1/2004, justifica-se por ser o limite mínimo permitido pelo Google Trends; e a data final, 31/12/2014, por compreender o ano mais recente com 12 meses completos, na época da coleta dos dados.

Os resultados apontam 50 termos de busca com a palavra "criatividade"; um ranking dos 27 estados brasileiros e das 15 cidades, segundo a quantidade de buscas que cada local originou; e um comparativo entre as 574 semanas ordenadas conforme o volume de buscas feitas em cada período. Tal listagem compõe o que Lopes (2014) chama de unidades de pesquisa, ou seja, fontes de informação obtidas por meio de técnicas de amostragem para delimitar o universo da investigação.

\section{Apresentação dos resultados}

Os dados fornecidos pelo Google Trends não espelham o comportamento de toda uma população, mas de uma parcela que tem acesso à internet e utiliza o Google como ferramenta de busca. De acordo com a Pesquisa Nacional por Amostra de Domicílio (PNAD) em 2014, 54,4\% da população com 10 anos ou mais acessou a internet nos três meses anteriores à pesquisa (IBGE, 2015, p. 69). Considerando que, na época, a população estimada no Brasil era de 203,2 milhões de pessoas, trata-se de 95,4 milhões de usuários potenciais do Google. Com base na PNAD, é possível extrair recortes por gênero, região geográfica e faixa etária e concluir que o percentual de mulheres que acessaram a internet é ligeiramente superior ao de homens; além disso, a maior parte dos acessos origina-se na região Sudeste, e a faixa etária mais frequente é de 30 a 39 anos.

Os resultados expostos na seção anterior indicam que, para os dez anos (20042014), foram encontradas 50 frases com o termo "criatividade", às quais o Google Trends atribuiu valores de 0 a 100 . Quando somados, esses valores alcançam a marca de 545 pontos, o que será utilizado como referencial para quantificar a representatividade das buscas unitárias em relação ao total, em termos de proporção.

A expressão mais frequente foi "a criatividade", à qual foram atribuídos 100 pontos. A proposição "criatividade é" apareceu em segundo lugar, com 40 pontos, enquanto os termos "inovação" e "sem criatividade" alcançaram 30 pontos cada. Com 25 pontos, aparecem as expressões "oficina criatividade" e "inovação e criatividade". Já o termo "oficina de criatividade" teve 20 pontos, e outros três registraram 15 pontos: "frases 
criatividade", "criatividade sem limites" e "criativo". Com 10 pontos, aparecem as expressões "oficina da criatividade", "livro criatividade", "criatividade infantil", "escola criatividade", "mais criatividade" e "frases de criatividade".

O Gráfico 1 apresenta os 50 resultados:

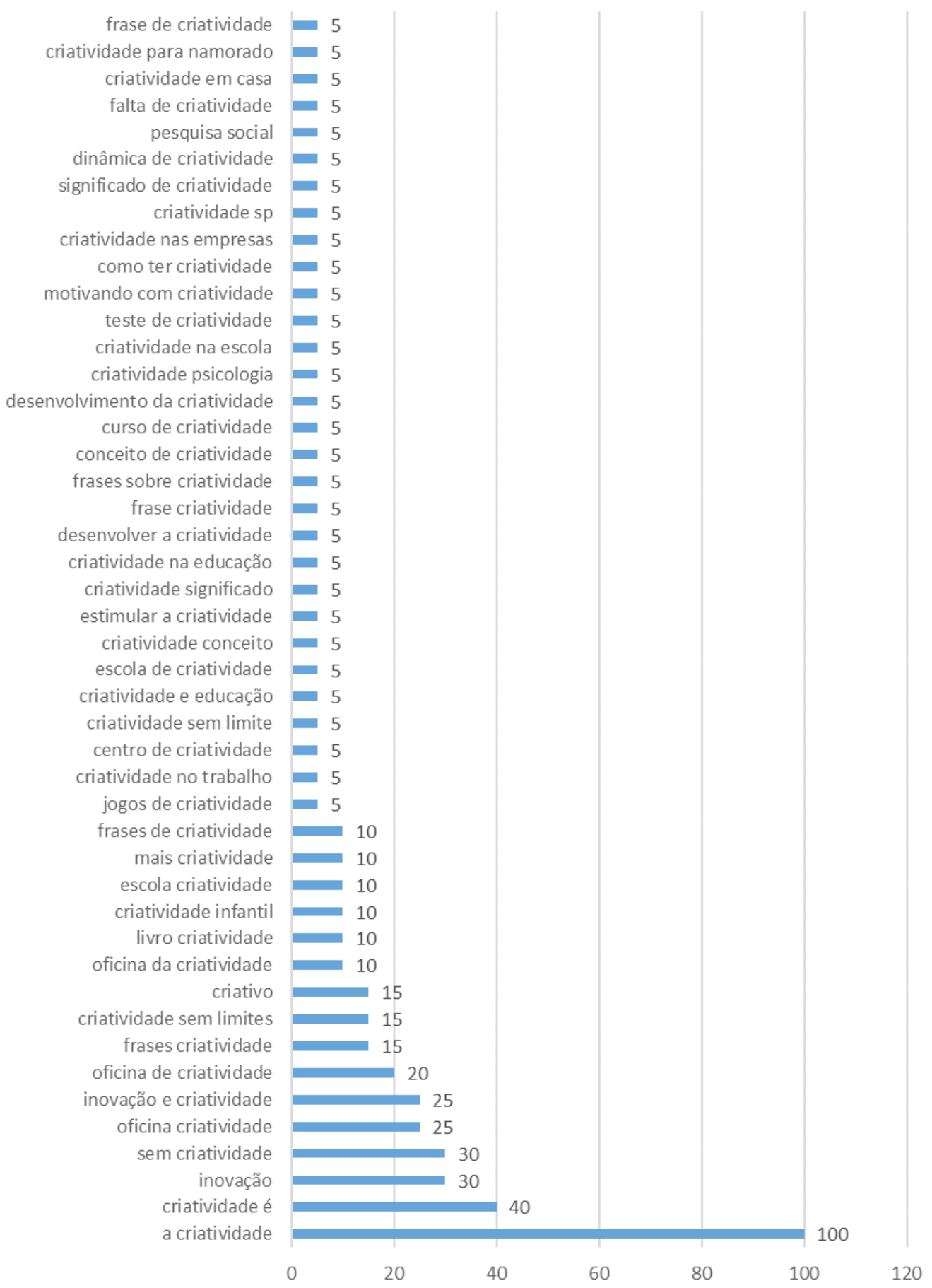

Gráfico 1. Buscas realizadas no Google com o termo "criatividade" entre 2004 e 2014.

Fonte: Elaborado pelos autores com base no Google Trends (2014). 


\section{Análise dos resultados}

Na sequência do Gráfico 1, identificamos correspondência entre 37 dos termos de busca e três tópicos das pesquisas acadêmicas em criatividade com foco predominantemente cognitivo, ficando a abordagem sociocultural para uma etapa posterior. Conforme a similaridade de significado, os resultados foram organizados em grupos cujos títulos em formato de "perguntas-tema" sintetizam conteúdos: Grupo 1: qual é o conceito de criatividade?; Grupo 2: é possível adquirir criatividade?; e Grupo 3: quem é criativo e como se mede a criatividade?

\section{Grupo 1: qual é o conceito de criatividade?}

Com 11 elementos, esse grupo representa 45,98\% das buscas analisadas e indica que mais de $1 / 3$ dos internautas estavam interessados em compreender o sentido da palavra e seus usos. Em ordem decrescente de interesse, os termos de busca que compõem esse grupo são "a criatividade", "criatividade é", "frases criatividade", "frases de criatividade", "criatividade conceito", "criatividade significado", "frase criatividade", "frases sobre criatividade", "conceito de criatividade", "significado de criatividade" e "frase de criatividade".

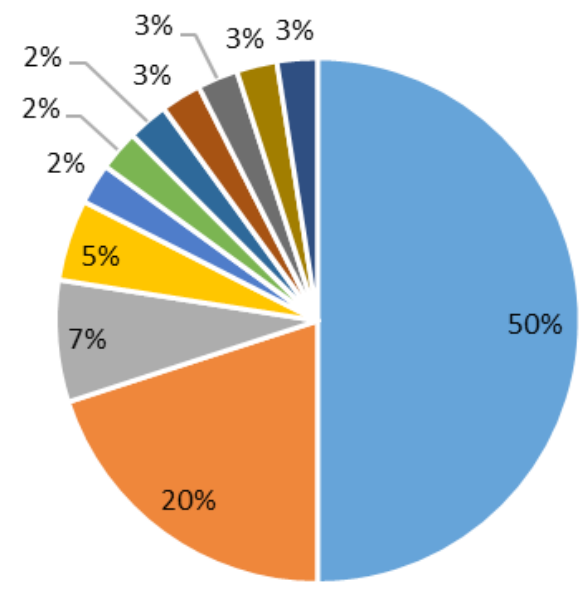

$$
\begin{aligned}
& \text { - a criatividade } \\
& \text { - criatividade é } \\
& \text { - frases criatividade } \\
& \text { - frases de criatividade } \\
& \text { - criatividade conceito } \\
& \text { - criatividade significado } \\
& \text { - frase criatividade } \\
& \text { - frases sobre criatividade } \\
& \text { - conceito de criatividade } \\
& \text { - significado de criatividade } \\
& \text { - frase de criatividade }
\end{aligned}
$$

Gráfico 2. Termos relacionados ao conceito "criatividade", segundo o interesse dos internautas. Fonte: Elaborado pelos autores com base no Google Trends (2017).

Apesar de teóricos contemporâneos pensarem na criatividade como um processo mais amplo e dinâmico, baseado na comunicação entre pessoas e nas demais interações com os objetos e fatores ambientais (GLĂVEANU, 2012), no senso comum, assim como 
entre autores mencionados a seguir, parece ainda persistir uma busca por suas evidências nas pessoas, denominando-as "criativas" ou "não criativas". E os elementos centrais desse atributo são a novidade e a adaptação (HENESSEY; AMABILE, 2011, p. 14).

Os dois elementos resumem definições acadêmicas de criatividade e apontam para um terceiro: o contexto. Lubart (2010, p. 347) chama a atenção para esse fator, pois "A cultura oferece uma série de condições facilitadoras e inibidoras para a criatividade e influencia o nível geral de atividade criativa". A proposição traz uma problematização já levantada por Bergson (1998) no que diz respeito a lidar com uma produção ou sensação nova, fundamental para refletir sobre criatividade e carência de respostas mais amplas entre estudiosos focados em quesitos cognitivos que ainda pautam significações da criatividade no senso comum, no contexto das duas seções seguintes. As produções da cultura envolvem desde descobertas científicas e tecnológicas até obras de arte, tendo cada gênero particularidades também no que diz respeito a criatividade.

No caso de obras de arte, muitas em contato com ampla audiência, ocorre uma avaliação do grau de contribuição para o domínio artístico, variável da repetição à ruptura no que diz respeito ao nível de originalidade (LUBART, 2007). A categorização pode se basear em critérios subjetivos, como o tipo de experiência propiciada ao espectador (NEGUS; PICKERING, 2004), e também no histórico das produções no mesmo domínio (CSIKSZENTMIHALYI, 2006) ou em diálogo com outros, ainda que este caracterize o que autores como Carrascoza (2008) apontam como bricolagem quando se trata da criação publicitária.

Albert e Runco (2006) mostram a evolução da definição de "criatividade" desde o período pré-cristão - quando era associada a poderes místicos - até o século 19, quando Galton aplicou métodos empíricos na seleção de sujeitos e na medição de diferenças individuais, questionando a ligação entre criatividade e misticismo e evidenciando a separação entre a genialidade e o sobrenatural. Galton ainda comprovou que a habilidade está distribuída de forma diversa por toda a população e reconheceu que cada indivíduo tem potencial para atuar de forma criativa, tendo sua contribuição prosseguido em pesquisas baseadas na abordagem sociocultural da criatividade (GLĂVEANU, 2014).

\section{Grupo 2: é possível adquirir criatividade?}

É o maior grupo, com 24 expressões, que representam 49,43\% das sentenças analisadas. Está dividido em três grandes subtemas: a possibilidade de desenvolver a criatividade ("sem criatividade", "criatividade sem limites", "livro criatividade", "mais criatividade", "jogos de criatividade", "criatividade sem limite", "estimular a criatividade", "desenvolver a criatividade", "curso de criatividade", "desenvolvimento da criatividade", 
"como ter criatividade", "dinâmica de criatividade" e "falta de criatividade"); a promoção da criatividade na infância ("criatividade infantil"); e os ambientes em que é possível estimular a criatividade ("oficina criatividade", "oficina de criatividade", "oficina da criatividade", "escola criatividade", "centro de criatividade", "criatividade e educação", "escola de criatividade", "criatividade na educação", "criatividade na escola" e "criatividade sp").

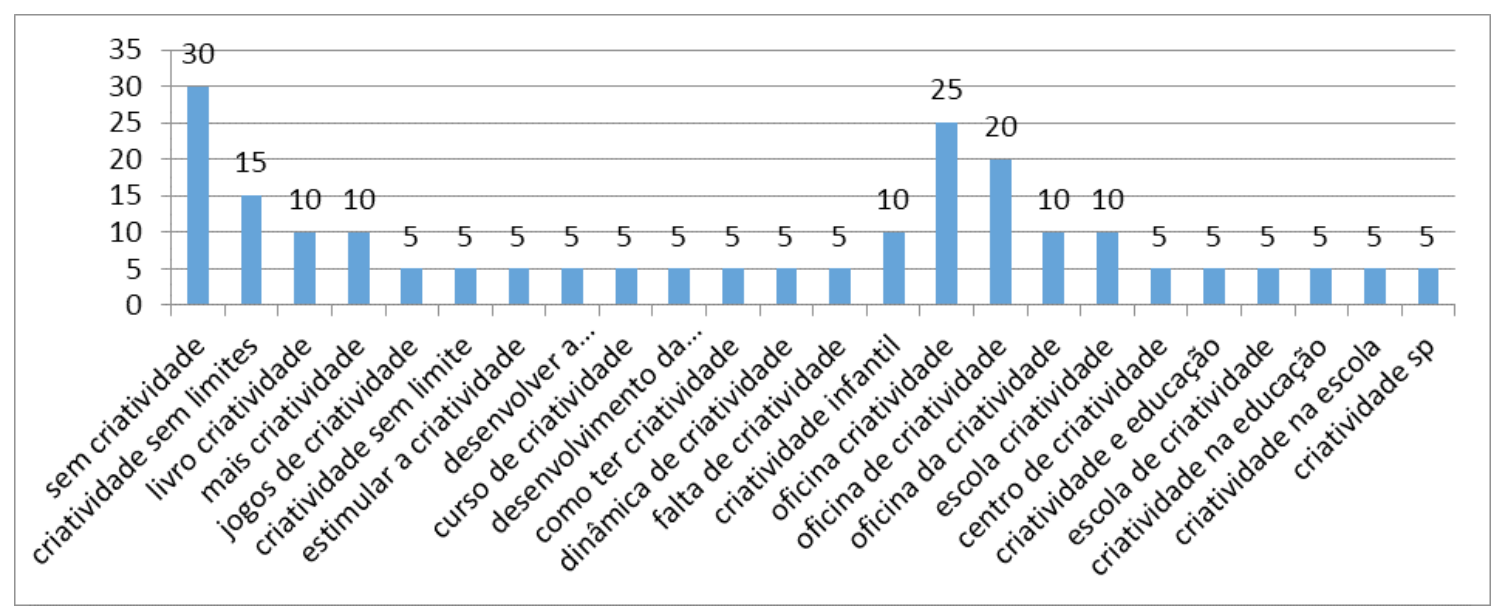

Gráfico 3. Termos relacionados à possibilidade de adquirir a criatividade - subtemas desenvolvimento, infância e ambientes

Fonte: Elaborado pelos autores com base no Google Trends (2017).

A importância dos fatores pessoais, sociais e ambientais para desenvolver a criatividade foi amplamente estudada, dando origem, inclusive, à abordagem sistêmica, segundo a qual a criatividade não é produto de indivíduos isolados, mas de um sistema social de julgamentos sobre produções individuais (CSIKSZENTMIHALYI, 2006). Para Hennessey e Amabile (2011, p. 11), independentemente do talento individual, da expertise de domínio e das habilidades de pensar criativamente, o ambiente social do indivíduo pode acrescentar ou diminuir o nível de criatividade. Lubart (2010, p. 339) também defende que a criatividade é um fenômeno contextual e que os ambientes nem sempre a estimulam. Na verdade, a promoção ou a proibição da atividade criativa varia bastante de um ambiente para o outro. Quatro importantes fatores são detalhados a seguir.

- Fator cultural - estudos historiométricos elaborados por Simonton (1997) demonstram que uma geração de inventores reconhecidos em uma sociedade prediz, em parte, o nível de criatividade das gerações seguintes naquele ambiente. Em contrapartida, Adams (1974, p. 57) identificou ideias que podem atuar como inibidoras e são amplamente disseminadas no ocidente, tais como "A fantasia e a reflexão são perda de tempo"; "Divertir-se é reservado às crianças"; e "A tradição é preferível à mudança". 
- Fator familiar - o impacto do ambiente familiar foi estudado por Rogers (1954) e Ochse (1990), que chegaram a conclusões opostas. Enquanto o primeiro sugere que esse ambiente pode ser favorável, caso apoiador, nutridor e relativamente não crítico, o segundo afirma que os aspectos limitadores são indispensáveis para estimular o comportamento criativo. Para Lubart (2007), as crianças tendem a ser mais criativas quando o ambiente familiar possui flexibilidade a partir de modificações feitas também por elas, pois ambientes familiares muito rígidos podem dar às crianças a representação de um mundo estático.

- Fator escolar - o ambiente escolar também é crucial no desenvolvimento da criatividade, pois tende a valorizar regras fixas para manter a ordem e adotar avaliações baseadas em memorização e pensamento convergentes para uma única resposta correta (LUBART, 2007). Porém, há escolas voltadas especificamente para o ensino da criatividade, como sugere o conteúdo significativo nas buscas deste segundo grupo (56\% das pesquisas), pelos termos de busca "oficinas", "centros", "cursos" e "escolas de criatividade". Nesses ambientes, o comportamento criativo é bem-vindo, desejável e passível de ser aprendido. Entre os resultados dessa abordagem mais prática e comercial, é relevante o termo "criatividade sp", em referência à cidade ou ao estado de São Paulo, o maior centro econômico do país e que, talvez por isso, tenha $(\mathrm{m})$ mais chances de reunir um maior número de manifestações criativas ou escolas de criatividade ${ }^{4}$.

- Fator profissional - por fim, a influência do meio profissional deve ser considerada quando se estuda as chances de desenvolvimento da criatividade. Lubart (2007, p. 81) aponta que tanto o tipo de atividade quanto o perfil favorável à expressão criativa das organizações são determinantes.

\section{Grupo 3: quem é criativo e como se mede a criatividade?}

O tema principal deste grupo, o criativo, é um dos mais importantes focos dos estudos sobre criatividade. Nos dados levantados, está presente nas buscas nos termos "criativo" e "teste de criatividade", os quais respondem por apenas $4,6 \%$ das buscas analisadas.

4 Segundo o Governo do Estado, São Paulo é a terceira unidade administrativa mais populosa da América do Sul. Ela tem a maior população do Brasil, está em terceiro lugar no ranking de Índice de Desenvolvimento Humano e é responsável por 28,7\% do PIB do país. Disponível em: <goo.gl/oqP8ia>. Acesso em: 28 jun. 2015. 


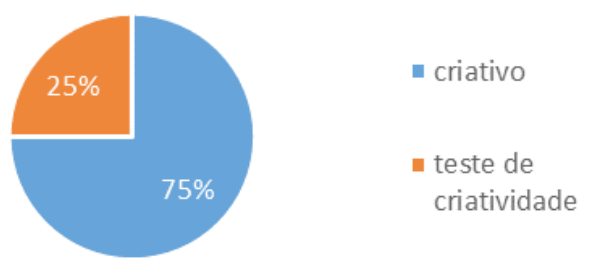

Gráfico 4. Termos relacionados ao indivíduo

Fonte: Elaborado pelos autores com base no Google Trends (2017).

Nas últimas quatro décadas, muitos pesquisadores da criatividade focaram as diferenças entre indivíduos - talento, experiência e personalidade - que distinguem uma pessoa altamente criativa de seus pares menos criativos (HENNESSEY; AMABILE, 2011, p. 34). A abordagem psicossocial se dedicou a estudar fatores pessoais, emocionais e socioculturais como fontes de criatividade e identificou alguns traços comuns às pessoas criativas: independência de julgamento, autoconfiança, atração pelo complexo, orientação estética e propensão ao risco (STERNBERG; LUBART, 2006, p. 8). Sternberg e Lubart (2006, p. 10) acreditam que vários elementos cognitivos e de personalidade devem convergir para a criatividade ocorrer, tais como: capacidade de conectar ideias, enxergar similaridades e diferenças; ter flexibilidade e gosto estético; opor-se aos modelos tradicionais; e ser motivador, inquiridor e questionador das normas sociais.

Então, quais são as características de uma pessoa criativa? Entre as habilidades mais citadas na literatura estão: fazer conexões e perguntas, usar a imaginação, pensar de maneira flexível e experimentar. Já as características pessoais mais comuns são: independência, autoconfiança e assertividade. Os atributos emocionais são: disposição, ambição e entusiasmo. No entanto, as características podem variar de uma cultura para outra. O senso de humor e a orientação estética ou artística, por exemplo, constituem um valor na cultura norte-americana, mas não na chinesa (LUBART, 2010, p. 270). Para Elisondo (2016, p. 362), uma das características dos criativos é abertura às novas experiências, realizadas em campos e contextos diferentes. Segundo Lubart (2007, p. 39), é possível identificar três aspectos ligados à pessoa no estudo da criatividade: os traços de personalidade, os estilos cognitivos e a motivação. Os dois primeiros já foram expostos. A motivação é abordada por Amabile (1996) em dois aspectos: a motivação intrínseca, que se refere ao motor ou aos desejos internos, satisfeitos com o cumprimento de uma dada tarefa; e a extrínseca, cujo foco é a recompensa oferecida pelo ambiente, após o cumprimento dessa tarefa.

O próximo tópico deste grupo é o teste de criatividade. Afinal, é possível medi-la? A abordagem psicométrica visa medir a criatividade de sujeitos comuns, por meio de testes escritos. Para Sternberg e Lubart (2006, p. 7), esses testes facilitam a pesquisa, 
pois possibilitam um instrumento de avaliação curto, fácil de administrar e objetivo. Por outro lado, as avalições podem ser acusadas de simplistas, e muitos critérios, de não serem adequados para capturar o conceito de criatividade para além do âmbito cognitivo. Neste, merece destaque o teste de pensamento divergente. Para Guilford (1967, p. 169), três índices permitem identificá-lo: a fluidez, a flexibilidade e a originalidade, que são, respectivamente, a capacidade de produzir muitas respostas; a capacidade de produzir muitas categorias de resposta; e a capacidade de gerar ideias raras. Já Lubart (2007) usa duas técnicas para avaliar a criatividade: questionários autoadministrados e medidas baseadas nas performances, avaliadas por juízes. $\mathrm{O}$ autor reconhece que uma das principais dificuldades do uso dos questionários é a natureza subjetiva das respostas, mas conclui que as medidas baseadas em performances são mais apropriadas para condutas criativas específicas a um domínio, enquanto os questionários conduzem a uma percepção criativa unitária. Apesar de amplamente utilizados, esses testes não são unânimes. Barrena (2007, p. 25) defende que as respostas dadas pela Psicologia são insuficientes no que diz respeito a esses testes.

Elisondo (2016) trata do julgamento da criatividade. Num estudo sobre cientistas criativos, ela aponta que, em geral, ideias inovadoras não são compreendidas no momento histórico em que são formuladas. Simonton (1990 apud KOZBELT; BEGHETTO; RUNCO, 2010, p. 25) destaca que pessoas criativas mudam a forma como as outras pensam e, por isso, devem ser persuasivas, pois: "A ênfase na persuasão significa que a originalidade do dia a dia pode não ser considerada criativa, já que é geralmente muito pessoal". Portanto, comunicar ideias é fundamental para a criatividade.

\section{Encaminhamentos}

Apesar de traços de personalidade e estilos cognitivos poderem dar pistas para a compreensão da criatividade, eles não podem ser considerados sua fonte principal ou seu aspecto determinante (GLǍVEANU, 2016). Entretanto, trata-se de uma compreensão mais ampla da criatividade e passível de avanços a partir de estudos na comunicação, sendo a pesquisa aqui apresentada um passo importante por apontar, no senso comum, uma trajetória correspondente à seguida pelos estudos acadêmicos de criatividade. Sendo assim, ainda persiste a crença no aprendizado da criatividade em cursos, oficinas, livros, e também em seu desenvolvimento principalmente na infância, por meio de práticas educativas. Este é o significado partilhado pelos internautas brasileiros que utilizaram o Google como ferramenta de busca entre 2004 e 2014, decorrente da forma como o termo se apresenta na comunicação variável do nível interpessoal ao dos mais diversos meios. 
A análise quantitativa e qualitativa dos resultados deste trabalho sugere ainda que os mesmos internautas reconhecem a existência do indivíduo criativo e a possibilidade de medir a criatividade. Isso também é defendido por alguns teóricos da área que, em vez de tentarem abrir uma janela para o novo - como faz Deleuze (2005) ao apresentar embasamentos para também o fazerem outros estudiosos não apenas do domínio específico da imagem -, acabam limitando o conceito de criatividade e tratando as ações criativas com foco predominante no indivíduo. Porém, além de reflexões teóricas sobre a importância da experiência estética para tratar da criatividade (NEGUS; PICKERING, 2004), existem também estudos focados em demonstrar a influência dos diversos tipos de interação social sobre a criatividade do autor de uma obra científica, artística, musical, cinematográfica, ou de design, com os níveis de interação categorizados em familiares e amigos, pares e estudantes (no caso da universidade), clientes e mantenedores, críticos e especialistas, e público generalizado de uma determinada produção (GLĂVEANU; LUBART, 2014).

Sobre a proximidade entre o entendimento popular do tema e as pesquisas acadêmicas referidas, verificou-se que existe uma relação positiva no que se refere ao conceito e às possibilidades de desenvolvimento de criatividade, mas o nível de interesse pelo indivíduo criativo e pelos testes de criatividade é inversamente proporcional entre os internautas analisados e as pesquisas teóricas. Isso aponta uma tendência de abertura para novas formas de compreender a criatividade não no domínio acadêmico e do senso comum separadamente, mas inclusive no diálogo entre ambos. A compreensão do potencial de significação deu-se por meio da observação dos termos de busca isolados ou em conjunto. No Grupo 1 - "Qual o conceito de criatividade?", pesquisas relacionadas ao entendimento do termo "criatividade" representam $45,98 \%$ do total de buscas realizadas, indicando que o interesse pela compreensão do tema existe tanto entre os internautas brasileiros quanto entre acadêmicos.

Já o Grupo 2, “É possível adquirir criatividade?", indica que a possibilidade de adquirir a criatividade é considerada por $49,43 \%$ das buscas realizadas, pois tal como nos estudos acadêmicos referidos, os significados dos termos de busca apontam o interesse de ampliar ou desenvolver o potencial criativo e os ambientes que possam favorecer esse processo. Esse grupo também sugere que alguns locais podem ser mais promissores para a aprendizagem criativa. No entanto, é preciso aprofundar a análise para descobrir quais estados e cidades seriam favoráveis ao desenvolvimento da criatividade e por quais razões. Outro quesito a ser considerado em futuras pesquisas é a aceitação de escolas criativas pela sociedade, uma vez que o modelo educacional atual é fortemente voltado para escolas tradicionais, valorizadas pelo índice de aprovação em vestibulares ou concursos similares, e não pelo estímulo ao pensamento divergente, por exemplo. 
O Grupo 3, "Quem é criativo e como se mede a criatividade?", trata do perfil do indivíduo criativo e dos testes de desempenho. Apesar de amplamente estudados pela academia, esses temas representam apenas 4,6\% dos termos de busca analisados. Seria em decorrência da falta de familiaridade com números e variáveis característicos dos testes e das pesquisas quantitativas sobre criatividade?

Diante do exposto, percebemos que os termos de busca utilizados no Google para pesquisar criatividade e os estudos acadêmicos a esse respeito seguem majoritariamente consoantes. Além disso, o aprofundamento dos dados apresentados e sua correlação com indicadores sociais e demográficos podem levar a indicativos inéditos sobre o interesse pela criatividade no Brasil. Até o momento, o foco do trabalho está na compreensão dos termos empregados nas buscas como representantes das ações e mediadores da comunicação dos internautas em busca de seus objetivos no que diz respeito ao conhecimento sobre criatividade. Tal compreensão é apenas um primeiro nível da comunicabilidade, entretanto fundamental na possível condução a outros níveis de significação capazes de contemplar ainda mais o novo (BERGSON, 1998), resultado esperado com a trajetória futura desta pesquisa e de outras.

\section{Referências}

ADAMS, J. L. Conceptual blockbusting: a guide to better ideas. 4. ed. New York: Addison-Wesley, 1974.

ALBERT, R. S.; RUNCO, M. A. A history of research on creativity. In: STERNBERG, R. J. (Ed.). Handbook of creativity. New York: Cambridge University Press, 2006. p. 16-31.

BARDIN, L. Análise de conteúdo. 1. ed. São Paulo: Edições 70, 2012.

BARRENA, S. La razón creativa: crecimiento y finalidad del ser humano según C. S. Peirce. Madrid: Ediciones Rialp, 2007.

BARROSO, J. M. Restoring Europe's social market economy through EU 2020. Bonn: European Union, 2009.

BERGSON, H. Creative evolution. Toronto: General Publishing, 1998.

BRASIL. Secretaria de Comunicação Social da Presidência da República. Pesquisa brasileira de mídia 2015: hábitos de consumo de mídia pela população brasileira. Brasília, DF: Secom, 2014. Disponível em: <goo.gl/pgShmU>. Acesso em: 26 out. 2017.

BRUNO, F. Máquinas de ver, modos de ser. 1. ed. Porto Alegre: Sulina, 2013.

CARRASCOZA, J. A. Do caos à criação publicitária: processo criativo, plágio e ready-made na publicidade. São Paulo: Saraiva, 2008.

CROPLEY, A. J. The dark side of creativity: what is it? In: CROPLEY, D. H. et al. (Eds.). The dark side of creativity. New York: Cambridge University Press, 2010. p. 1-14. 
CSIKSZENTMIHALYI, M. Implications of a systems perspective for the study of creativity. In: STERNBERG, R. J. (Ed.). Handbook of creativity. New York: Cambridge University Press, 2006. p. 313-335.

DEFOSTER, R. Orientalism for a new millennium: cable news and the specter of the "Ground Zero Mosque”. Journal of Communication Inquiry, Thousand Oaks, v. 39, n. 1, p. 63-81, 14 jul. 2014.

DELEUZE, G. A imagem-tempo. São Paulo: Brasiliense, 2005.

ELISONDO, R. C. Creatividad y ciencias. Un estudio biográfico de científicos argentinos. Ciência, Docência e Tecnologia, Conceição do Uruguai, v. 27, n. 52, p. 343-380, 2016.

FERNÁNDEZ-REYES, R.; PIÑUEL-RAIGADA, J. L.; VICENTE-MARIÑO, M. La cobertura periodística del cambio climático y del calentamiento global en El País, El Mundo y La Vanguardia. Revista Latina de Comunicación Social, [S.1.], v. 70, n. 2, 122-140, 2015.

GLĂVEANU, V. P. Rewriting the language of creativity: the five A's framework. Review of General Psychology, Washington, DC, v. 17, n. 1, p. 69-81, 2012.

The psychology of creativity: a critical reading. Creativity: Theories - Research-Applications, Varsóvia, v. 1, n. 1, p. 10-32, 2014.

. The psychology of creating: a cultural-developmental approach to key dichotomies within creativity studies. In: . (Ed.). The Palgrave handbook of creativity and culture research. Londres: Palgrave Macmillan, 2016. p. 205-223.

GLĂVEANU, V. P.; LUBART, T. Decentring the creative self: how others make creativity possible in creative professional fields. Creativity and innovation Innovation Management, New York, v. 23, n. 1, p. 29-43, 2014.

GOOGLAR. In: WIKIPÉDIA, a enciclopédia livre. Flórida: Wikimedia Foundation, 2017. Disponível em: <goo.gl/eruA8j>. Acesso em: 26 out. 2017.

GOOGLE TRENDS. Google Trends. 2015a. Disponível em: <goo.gl/sE7os4>. Acesso em: 10 maio 2015. . Criatividade. 2015b. Disponível em: <goo.gl/qEshPC>. Acesso em: 10 maio 2015.

. How trends data is adjusted. 2015c. Disponível em: <goo.gl/59xK23>. Acesso em: 5 out. 2015. . Where trends data comes from. 2015d. Disponível em: <goo.gl/gRU5JE>. Acesso em: 10 maio 2015.

GOVEIA, F. G.; CARREIRA, L. S. Fotografia e big ata: implicações metodológicas. In: CONGRESSO BRASILEIRO DE CIÊNCIAS DA COMUNICAÇÃO, 36., 2013, Manaus. Anais eletrônicos... Manaus: Intercom - Sociedade Brasileira de Estudos Interdisciplinares da Comunicação, 2013. Disponível em: <goo.gl/aA1NLC>. Acesso em: 25 out. 2017.

GUILFORD, J. P. The nature of human intelligence. New York: McGraw-Hill, 1967.

HENNESSEY, B. A.; AMABILE, T. M. The conditions of creativity. In: STERNBERG, R. J. (Ed.). The nature of creativity. New York: Cambridge University Press, 2011. p. 11-38.

IBGE. Pesquisa nacional por amostra de domicílios: síntese de indicadores 2014. 1. ed. Rio de Janeiro: IBGE, 2015. 
KOZBELT, A.; BEGHETTO, R. A.; RUNCO, M. A. Theories of creativity. In: KAUFMAN, J. C.; STERNBERG, R. J. The Cambridge handbook of creativity. New York: Cambridge University Press, 2010. p. 20-47.

LOPES, M. I. V. Pesquisa em comunicação. 12. ed. São Paulo: Loyola, 2014.

LUBART, T. Psicologia da criatividade. Porto Alegre: Artmed, 2007. . Cross-cultural perspectives on creativity. In: KAUFMAN, J. C.; STERNBERG, R. J. (Eds.). The Cambridge handbook of creativity. New York: Cambridge University Press, 2010. p. 265-279.

MARCONDES FILHO, C. Teorias da comunicação hoje. São Paulo: Paulus, 2016.

NABI, Z. Resistance censorship is futile. First Monday, Chicago, v. 19, n. 11, 2014.

NEGUS, K.; PICKERING, M. J. Creativity, communication and cultural value. Londres: Sage, 2004.

O'CONNOR, Brendan. The sad, true story of the Ground Zero Mosque: how the 'Ground Zero Mosque' became 'above market-rate' luxury condos. The Awl, New York, oct. 2015. Disponível em: <https:// goo.gl/kkzh8R >. Acesso em: 8 maio 2016.

OCHSE, R. A. Before the gates of excellence: the determinants of creative genius. New York: Cambridge University Press, 1990.

OLHAR DIGITAL. Confira o ranking dos buscadores no Brasil. 2015. Disponível em: <goo.gl/WYj3Ap>. Acesso em: 3 maio 2015.

ROGERS, C. R. Toward a theory of creativity. ETC: A Review of General Semantics, New York, v. 11, n. 4, p. 249-260, 1954.

SIMONTON, D. K. Creative productivity: a predictive and explanatory model of career trajectories and landmarks. Psychological Review, Washington DC, v. 104, n. 1, p. 66-89, 1997.

Simonton, D. K. History, chemistry, psychology, and genius: An intellectual autobiography of historiometry. In: RUNCO, M. A.; Albert, R. S. (Eds.). Theories of creativity. Newbury Park, CA: Sage, 1990. p. 92-115.

STERNBERG, R. J.; LUBART, T. The concept of creativity: prospects and paradigms. In: STERNBERG, R. J. (Ed.). Handbook of creativity. New York: Cambridge University Press, 2006. p. 3-15.

STUMPF, I. R. C. Pesquisa bibliográfica. In: DUARTE, J.; BARROS, A. (Ed.). Métodos e técnicas de pesquisa em comunicação. 2. ed. São Paulo: Atlas, 2012. p. 51-61

VARSHNEY, L. R. et al. A big data approach to computational creativity. In: THE IEEE INTERNATIONAL CONFERENCE ON COGNITIVE INFORMATICS AND COGNITIVE COMPUTING, 12. Calgary. Anais... Calgary: IEEE - The Institute of Electrical and Electronics Engineers, 2013. p. $1-16$. 